\title{
Alteridade e raça entre África e Brasil: branquidade e descentramentos nas ciências sociais brasileiras'
}

Dol

http://dx.doi.org/10.11606/ 2179-0892.ra.2020.170727

\section{Luena Nascimento Nunes Pereira}

Universidade Federal Rural do Rio de Janeiro / Rio de Janeiro, R], Brasil

luena.ufrri@gmail.com | https://orcid.org/0000-0001-8262-1342

RESUMO

A partir da minha experiência de campo em Angola, busco problematizar a tradicional caracterização da antropologia brasileira — e por extensão das ciências sociais como feita por "brasileiros" sobre o "Brasil", refletindo sobre o novo perfil dos cientistas sociais quanto ao pertencimento étnico, racial e de classe que tem se pluralizado nos últimos 20 anos. Esta transformação do perfil dos cientistas sociais desafia a ideia de um "nós antropológico" centrado em uma ideia naciocêntrica que não reconhece sua posição de classe, raça e território, ou seja, branca, de classe média, oriunda ou socializada no sul/sudeste do país. Defendo o descentramento das ciências sociais brasileiras inspirada pelos novos movimentos de descolonização das ciências sociais. Esse descentramento passa pelo reconhecimento e politização da branquidade hegemônica das ciências sociais como condição para sua revisão crítica.

Otherness and Race Between Africa and Brazil:

Whiteness and Decentering in the Brazilian Social Sciences

ABSTRACT From my field experience in Angola, I seek to question the traditional characterization of Brazilian anthropology — and by extension of the social sciences — as made by "Brazilians" about "Brazil", reflecting on the new profile of social scientists regarding ethnic belonging, racial and class that has pluralized for the past 20 years. This transformation of the profile of social scientists challenges the idea of "us the anthropologist" built on a nation-centered idea that does not recognize its class, race and territory, i.e. white, middle class, or socialized status in the south / southeast of the country. I defend the decentering of the Brazilian social sciences inspired by the new movements of decolonization of the social sciences. This decentering involves the recognition and politicization of the hegemonic whiteness of the social sciences as a condition for its critical revision.

Ciências Sociais, Antropologia Brasileira, Raça, Branquidade, Alteridade.
KEYWORDS

Social Sciences, Brazilian Anthropology, Race, Whiteness, Alterity 
Partilho com vocês estas reflexões ${ }^{2}$ motivada pela novidade notada nos últimos anos na universidade brasileira na qual ocorreu uma importante pluralização étnica e de classe. Essa pluralização foi um fenômeno geral na graduação e na pós graduação. Mas gostaria de pensar sobre o que ela nos permite refletir sobre o fazer das ciências sociais no Brasil.

Passadas duas décadas após o intenso debate que muitos de nós presenciamos em diversos fóruns políticos e acadêmicos sobre as cotas na universidade, assistimos à entrada de estudantes de graduação vindos majoritariamente de escolas públicas, negros, indígenas, fenômeno que se deve não apenas às cotas, mas também pela interiorização dos campi universitários e à ampliação de vagas que se faz sentir fortemente no norte e no nordeste do país ${ }^{3}$. Alguns anos depois tivemos uma expansão importante da pós-graduação e o mesmo processo se repetiu, em especial nas pósgraduações das áreas de ciências sociais e humanidades em geral, mas não apenas.

Esse processo não foi interrompido, ainda, por este novo período que se concretizou a partir do golpe de 2016. Entretanto, a ansiada fase de uma diversificação do corpo docente em termos étnico-raciais ainda aguarda o seu momento.

É a partir deste espaço-tempo (Quijano, 2005) da crise, a maior vivida pela minha geração, formada na chamada Nova República, que me permito pensar sobre algumas questões suscitadas pelas políticas de expansão da universidade pública e as ações afirmativas. Entendo que os momentos de crise podem ser produtivos para aprofundar a reflexão sobre tensões que se mantiveram latentes e que, por não poderem ser externadas, vivem nos assombrando e impedindo novos movimentos e transformações.

É importante ressaltar que eu falo a partir do lugar de professora de antropologia de uma universidade situada na Baixada Fluminense ${ }^{4}$. Tenho também como referência para esta fala um recém-criado coletivo de antropólogos negros e antropólogas negras ${ }^{5}$ que vem buscando refletir sobre as condições do fazer antropológico no Brasil a partir desta condição6.

\section{II}

Parto da minha experiência de campo em Angola e dos desafios que a minha condição de estrangeira e mestiça me impuseram em campo, para pensar sobre como corpos negros podem fazer diferença na chamada antropologia brasileira, até agora majoritariamente produzida por corpos brancos que raramente se pensam a partir deste lugar.

Eu me permito colocar entre aspas tanto os termos mestiça como estrangeira, porque eu começo com a questão trivial que a antropologia brasileira, tal como as ciências sociais brasileiras, é basicamente uma Antropologia do Brasil. A gente sabe que em países centrais fazer antropologia significa pesquisar realidades extra nacionais. Já o Brasil se constituiu como um campo de estudo privilegiado para a nossa academia, especificamente, quando falamos em ciências sociais. Isso significa dizer que as ciências sociais se propõem à tarefa de pensar o Brasil e suas diferentes
1 Este é o texto da Conferência proferida no $43^{\circ}$ Encontro Anual da ANPOCS, em 23 de outubro de 2019. Nesta versão foram acrescentadas notas explicativas e complementares, além da bibliografia.

2 | Agradeço aos meus colegas Ana Paula Miranda, Ana Paula Ribeiro, Caroline Freitas, Katucha Bento, John Comerford e Márcia Lima que contribuíram com a feitura deste texto.

3| Importante destacar que, junto com as cotas, a expansão dos campi universitários para o interior dos estados produziu uma inédita perspectiva de entrada na universidade no imaginário de jovens periféricos, não somente negros e indígenas, como também jovens oriundos de área rural $\mathrm{e}$ de famílias menos abastadas de pequenas cidades. Embor não seja incomum a presença na universidade de jovens de origem camponesa, desta vez temos jovens que continuam a manter forte conexão com os territórios rurais.

4|A Baixada Fluminense abrange os municípios da região metropolitana ao norte e oeste da cidade do Rio de Janeiro. Concentra cerca de um quarto da população do estado do Rio de Janeiro e apresenta baixos índices no que diz respeito a renda, IDH, saneamento básico, educação e outros.

5 | O “Coletivo de antropólogxs negrxs" foi criado no contexto da $31^{\mathrm{a}}$ Reunião Brasileira de Antropologia durante a produção de uma moção, apresentada na Assembleia da Associação Brasileira de Antropologia de repúdio a sucessivos fatos, entendidos como racistas e de invisibilização contra negras e negras ocorridos nesta e em reuniões anteriores da ABA. A moção pode ser encontrada na página da $A B A$ http://www.portal.abant. org.br/mocoes/.

6 | Esta não é uma posição de representação, nem de grupos nem de coletivos de antropólogos e antropólogas negras. 
realidades e contextos a partir daquilo que Mariza Peirano apontou como associado ao projeto de nation building (Peirano, 1999).

Então falo a partir da minha pesquisa cujo tema é Angola, no continente africano, na expectativa de que isso produza uma reflexão de certa forma diferenciada para a Antropologia ou para as ciências sociais no Brasil, que é de onde eu produzo, pesquiso e ensino. Talvez, seja ponto de partida interessante porque é uma condição relativamente descentrada.

A Antropologia se constrói como uma ciência eminentemente comparativa, sobretudo entre etnografias realizadas em diferentes contextos, e orientada por uma teoria que se pretende universal. Entretanto, ela não se separa de uma certa experiência também pessoal de se confrontar com contextos distintos e de como isso produz conhecimento a partir do seu lugar, sua origem, seus pertencimentos, seus valores. Vários antropólogos discutiram isso, mas talvez alguns aspectos não tenham sido suficientemente explorados no sentido de que boa parte dessas posições e pertencimentos foram naturalizados na produção do conhecimento.

No meu caso, eu trabalhei em Angola sobre a identidade étnica e nacional dos regressados. Os chamados regressados são uma parte do grupo Bakongo, um dos principais grupos étnicos que está presente em Angola e no Congo, na África Centro-ocidental. Eles fizeram uma trajetória de exílio no Congo durante a guerra de libertação nos anos 60 e retornaram para a capital Luanda após a independência, que se deu em 1975. Eu estudei a inserção desse grupo migrado construído como estrangeiro em Angola, no final dos anos 90. Eles são ex-exilados, mas foram por diversos motivos vistos como estrangeiros no contexto de Angola, em especial na capital (Pereira, 2000).

Eu também tinha a experiência de ser estrangeira em Angola, entretanto eu tinha, ainda tenho, uma família angolana, que é a família dos meus irmãos mais velhos, da primeira esposa do meu pai. Esta família me recebeu todas as vezes em que lá estive. Isso é um aspecto importante tanto do ponto de vista da pesquisa de campo quanto da minha experiência pessoal.

$\mathrm{Na}$ antropologia a gente pensa essas situações como experiências de alteridade, de estranhamento, de familiaridade, quer dizer, são jogos de aproximações e afastamentos que fazemos para compreender as lógicas classificatórias e pensar como se constroem as diferenças, as percepções da diferença, para pensar o chamado "outro" que é, como todos nós sabemos, um processo relacional.

Eaí é que no processo de pesquisa, em Angola, eu parti dessa situação familiar, no sentido da minha família mesmo, e também no sentido das aproximações históricas e culturais que ligam Angola e Brasil7. Entretanto, houve também um contexto identitário no qual sou negra no Brasil, mas em Angola eu fui reposicionada do ponto de vista racial como mestiça, e isso trouxe questões importantes que dialogam com o campo das ciências sociais brasileiras.
Entretanto sou estimulada pela noção de Aílton Krenak de sujeito coletivo (Krenak, 2018) que sugere a construção de saberes comuns através da vivência e da troca de experiências comuns, embora não homogêneas, que incluem memórias, heranças, saberes de antepassados. Esse sujeito coletivo no sentido que Krenak descreve me possibilita pensar que este texto não é exatamente de autoria coletiva, mas as ideias aqui desenvolvidas são profundamente devedoras de um espaço compartilhado, ainda que em muito virtual, habitado e dialogado entre antropólogas e antropólogos negros.

$7 \mid$ As relações entre Angola e Brasil são múltiplas e com uma história extensa que remete ao período do tráfico de escravizados e se desdobra na circulação de africanos e luso-brasileiros pelo Atlântico. O período colonial africano e a reação anticolonial foi marcada pela disputa política e diplomática por apoios tanto às pretensões coloniais portuguesas - que tiveram no governo brasileiro até 1961 um aliado constante - como dos nacionalistas africanos que buscaram espaços de apoio na sociedade civil brasileira à luta anticolonial (Lima, 2017). Houve importante circulação entre os territórios africanos, Portugal e Brasil de nacionalistas africanos, militantes brasileiros e antissalazaristas, bem como da literatura brasileira que inspirou escritores angolanos (bem como intelectuais das outras colônias portuguesas) a produzirem uma literatura nacional em língua portuguesa. 
Isto porque existeum campo importante de estudos de relações raciais no Brasil que sempre pensou comparativamente tendo como parâmetro os Estados Unidos. As relações raciais sempre foram pensadas na relação com o modelo norte-americano. Mais recentemente trabalhou-se com a ideia de comparações de matriz colonial (Fry, 1991, 2003, 2005). Apesar da origem freyriana dessa comparação colonial, nos anos 90 se constituiu aqui mais ou menos a ideia de colonialismo comparado, com a suposição de que haveria uma identidade, ou seja, características comuns entre países de mesma colonização8.

Desse modo, Brasil, Angola e Moçambique estariam relativamente muito mais próximos do que países de colonização britânica, como Zimbábue, África do Sul e Estados Unidos. Então, quando eu fui pra Angola, eu não estava pensando em relações raciais comparadas, não era esse o meu interesse, mas me vi na posição de negra no Brasil e de mulata em Angola. Inequivocamente eu sou mulata em Angola e isso não tem o mesmo significado que teria no Brasil. Eu vou usar o termo "mulata" porque é esse o termo que se usa lá. Então, essa questão da relação racial comparada não era meu campo de pesquisa, mas eu tive que me reposicionar nesse sentido como mulata em Angola, e isso posteriormente me fez pensar que, claro, eu estava em um outro sistema de classificação que se parece com o Brasil, mas não é a mesma coisa.

Ou seja, emerge o sentido dado por Gilberto Freyre $(2003[1933])^{9}$ e depois essa ideia problemática de lusofonia nos países de língua portuguesa, que supõe haver uma identidade comum a partir de um eixo colonial ou pós colonial que seria evidenciada pelo uso da língua portuguesa, que sabemos também que não tem o mesmo peso, nem extensão e tampouco sentido em todos esses países ${ }^{10}$.

E na verdade sabemos que essa identidade é muito enganadora, pois essa familiaridade traz equívocos, que é a suposição de que se está dizendo mestiço ou mulato no Brasil, em Angola ou em Moçambique, como se estivesse falando a mesma coisa, mas não estamos falando da mesma coisa de jeito nenhum. Então, todo o meu campo em Angola, durante o mestrado, foi trabalhar com esse processo antropológico de familiarização, desfamiliarização, exotização, desexotização de tentar entender como é que se constituía a diferença e o processo de estrangeirização dos ex-exilados em Luanda e do reposicionamento deles a partir desse lugar de estrangeiros.

Estes ex-exilados não estavam na sua região de origem, que era o norte de Angola, mas em Luanda construindo um mercado informal, muito associados aos congoleses, entretanto, afirmando uma identidade angolana, uma identidade africana e angolana a partir de uma ideia de origem dos seus pais e seus avós.

A origem, no caso dos Bakongo, foi muito mais importante na reivindicação da nacionalidade do que a terra de nascimento, que foi a forma pela qual os angolanos brancos e mestiços pensaram pertencimento nacional. Para estes brancos e mestiços era vital essa ideia, digamos, republicana, de pertencimento a partir do território e não a partir da origem, porque, claro, esses brancos e mestiços eram filhos dos
8| Fry apresentou um primeiro argumento em 1991 no qual defendeu uma distinção entre as formas da colonização britânica e portuguesa de operarem relações coloniais e raciais. A primeira teria produzido uma visão mais rígida da diferença racial e a segunda seria responsável por uma visão mais "relacional", mais assimilacionista $\mathrm{e}$, portanto, menos essencialista, ainda que racializada (1991). Ela explicaria a diferença entre os casos moçambicano e sul-africano do mesmo modo que os casos brasileiro e estadunidense. Essa transposição mais direta entre os casos português e britânico na África e na América foi matizada depois nos textos de 2003 e 2005 , aprofundando a distinção britânica e portuguesa apenas na análise do caso moçambicano em comparação ao Zimbábue.

9|As obras onde Gilberto Freyre desenvolve a noção de lusotropicalismo são especialmente nos seus escritos resultantes das viagens às colônias portuguesas nos anos 1950 e 1960 (O mundo que o português criou, Aventura e Rotina, Um brasileiro em terras portuguesas), mas a ideia central do protagonismo português que cria um modo próprio e original de colonizar já está presente no clássico Casa Crande \& Senzala [1933].

10| Sobre críticas a noção de lusofonia, ver especialmente Alfredo Margarido (2000). Sobre pós-colonialismo no caso português, ver Miguel Vale de Almeida (2007). 
colonos portugueses que estavam sendo expulsos de Angola na altura da independência. Já no caso dos filhos dos angolanos nascidos no Congo, e que voltavam do exílio para Angola, a chave do pertencimento era a origem, a ancestralidade.

Eu também estava construindo meu lugar em uma família angolana, que é a família dos meus irmãos mais velhos, com a qual eu tinha uma relação de proximidade, acolhimento, mas ao mesmo tempo de estranhamento. Porque não era minha família de criação. Era uma família situada na capital, mas cuja origem remetia às antigas e importantes famílias quimbundo do século XIX. Eu, ao mesmo tempo que estava tentando me familiarizar com o universo regressado, também estava tentando encontrar um certo lugar numa família que achava que os regressados que eu estudava eram a coisa mais exótica, mais esquisita, menos angolana que eu poderia estudar.

Foi a experiência de aproximação, afastamento, identidade e contraste que me fez construir o meu mestrado. Entretanto, no doutorado eu retorno para o campo, me afastando do interesse na luta identitária, desse processo de contraste de construção do um, através da alteridade radical que se projeta no outro.

Assim, eu resolvi estudar não mais apenas os regressados, mas a população Bakongo em Luanda como um todo, a partir dos processos de sociabilidade e poder local a partir do estudo de parentesco e da emergência de igrejas cristãs, entre as quais as igrejas pentecostais e as igrejas africanas (Pereira, 2005, 2012, 2015). Ou seja, como se cruzavam as redes familiares e as redes de igrejas a partir da construção de lideranças nas cisões e proliferações das igrejas cristãs.

Assim me vi em uma outra rede, nessa rede de famílias e igrejas, me vi visitando uma igreja diferente a cada domingo e acompanhando os cultos de mulheres de uma igreja específica durante a semana. ${ }^{1 "}$ Então, o tempo inteiro que circulava por diferentes igrejas eu era perguntada pela minha identidade religiosa, porque não tinha como eu estar nas igrejas, mesmo sendo estrangeira, mesmo sendo branca, sem pertencimento nenhum.

É importante dizer que em certos circuitos dos Bakongo eu sou lida como branca, que é uma coisa fantástica porque para uma parte do grupo, sobretudo aqueles que vieram do Congo, eles não pensam nesse termo mestiço da maneira como os luandenses pensam. Eles são bem mais binários e isso tem a ver com o contexto congolês, tem a ver também com aspectos da cosmologia bakongo de um pensamento mais dualista.

Sendo assim, eu fui branca várias vezes, e isso gerou algumas questões internas pessoais muito complexas porque eu já era muitas coisas em Angola. Eu tinha que lidar com homens velhos sendo, na época, jovem; eu tinha que lidar com mulheres e eu não tinha filhos; além de ser brasileira, o que implica lidar com vários imaginários do Brasil que circulam em Angola e por vezes passam pelo viés do neocolonialismo e do imperialismo cultural' ${ }^{12}$ (Pereira, 2013).

Mas, no vai e vem das igrejas, eu tinha que me posicionar religiosamente, e em um certo momento eu resgatei minha herança católica. Nasci em família católica.
11 Angola é considerado um dos países mais cristianizados da África, com reduzida presença muçulmana. As estatísticas apresentam um cristianismo da ordem de $90 \%$ cuja maioria seria católica e a outra metade se dividiria entre protestantes históricos, herdeiros das missões coloniais, e a crescente proliferação evangélica pentecostal das últimas décadas. Há que se considerar, dentro do universo protestante, a não desprezível presença das igrejas africanas, herdeiras dos movimentos religiosos da contestação anticolonial. As estatísticas não levam em consideração a relação entre o pertencimento a religiões e igrejas formais e a continuidade de práticas tradicionais. Assim, as chamadas "religiões tradicionais", nessa lógica de classificação exclusivista, contaria com cerca de $5 \%$ de adeptos.

12 O período da independência angolana, e posterior, assiste a 
Depois eu me afastei do catolicismo e fui para o candomblé, mas eu não tinha como traduzir isso porque traduzir candomblé em Angola, diferente do senso comum daqui, em Angola não tem candomblé, não tem culto de orixás. Há algo muito mais sutil, que são os vários cultos chamados tradicionais, em uma lógica muito diferente do chamado "candomblé Angola" do Brasil. Então, se lá eu dissesse "candomblé" eu seria acusada de ser feiticeira, e eu não tinha como explicar. E acabou por fazer mais sentido para mim e para as pessoas dizer que eu era católica.

Então me reposicionei como católica e não era uma questão de fingir, mas como uma maneira de negociar um posicionamento que existe no sistema de classificação daquele contexto. Do contrário, eu não teria como traduzir a minha legitimidade de estar nas igrejas, nem de circular entre elas. Eu podia circular sim, enquanto pesquisadora, estrangeira, branca; mas circular sem uma posição, eu não tinha como ser lida. Eu não tinha como ler.

Então, na verdade foram essas chaves do sistema de classificação religioso que me fizeram perceber como a religião era crucial na marcação dos Bakongo, tanto na composição interna do grupo, e na maneira pela qual eles se pensavam internamente, como na identidade veiculada para fora.

Portanto, a chave para entender o sistema político de parentesco e para pensar a articulação da identidade étnica e nacional dos Bakongo era entender a rede das igrejas, e eu só fui entender isso quando eu me reposicionei como católica ${ }^{13}$.

Isso foi curioso porque ser católica em Angola representa al gumas coisas muito interessantes: é uma igreja de maioria, apresenta uma posição de certa neutralidade étnica e ideológica. Então, ser católica também é dizer de algum lugar neutro, de uma falsa neutralidade, porque é hegemônico. Ser católico simplifica, se coloca num lugar fácil de ser identificado, mas para mim foi muito difícil, porque quando eu voltei, fui refletir, rever o meu caderno de campo, pensar, escrever e olhar para essa posição passou a ser um tanto quanto esquisito.

Como era esquisito também ser branca ou mulata em Angola. Porque ser mulato é estar em uma posição absolutamente minoritária, muito diferente do Brasil ${ }^{14}$. Ser mulato no Brasil é uma posição maioritária no sentido do mestiço poder querer dizer muitas coisas e pode querer dizer coisa nenhuma. Na verdade, é nesse sentido de não dizer nada é que ideia de "mestiço" se coloca no Brasil (Figueiredo e Crosfoeguel, 2010).

Mas em Angola ser mestiço ou mulato é estar em um lugar muito marcado, associado ao privilégio, não tanto do ponto de vista econômico ou social, mas em um lugar de privilegio no sentido simbólico, e em um lugar de uma certa síntese nacional. Ser mulato em Angola ressoa sobretudo dizer de um lugar entre a africanidade e a ocidentalidade que marca um certo ser nacional que os brancos em Angola não têm. Portanto é um lugar extremamente confortável, embora por vezes muito arrogante e sujeito a ofensas e alvo de ressentimentos. É diferente da uma aproximação sem precedentes entre Brasil e Angola marcada pelo surpreendente reconhecimento do governo militar brasileiro à independência angolana declarada pelo movimento de libertação autodeclarado socialista, MPLA. A presença brasileira em Angola se traduz pelo apoio político, pelo intenso comércio entre os dois países e pela presença de várias empresas, com destaque para a empreiteira Odebrecht, devido à longa atuação em Angola. A Odebrecht durante décadas pode ser percebida quase que como uma segunda embaixada brasileira em Angola. Do ponto de vista cultural, além da já mencionada influência da literatura modernista brasileira, as novelas sempre foram avidamente consumidas em Angola e responsáveis por muito do imaginário angolano sobre o Brasil desde os anos 1970. A música brasileira, em seus diversos estilos, também contribuiu para este imaginário desde o período colonial. Já a circulação de angolanos no Brasil remete à presença das chamadas "sacoleiras", pessoas que fazem compras de roupas e outros objetos revendidos em Angola, muito comum nos anos 1980 e 1990, como de estudantes e também de refugiados. A primeira onda de refugiados se deu a partir de 1992, no reinício da guerra civil após as eleições de 1991.

13 A religiosidade e as adesõe religiosas de cientistas sociais não tem recebido a atenção merecida na reflexão sobre a construção do conhecimento antropológico. Remeto ao trabalho fundamental de Vagner Conçalves da Silva (2000) sobre a relação entre antropólogos e adeptos das religiões de matrizes africanas e a um estudo de Regina Novaes (1994) sobre pertencimento religioso dos estudantes de ciências sociais no Rio de Janeiro.

14 | Os chamados "mestiços" em Angola não devem chegar a $5 \%$ da população total e os brancos angolanos, a menos de $1 \%$. Cabe ressaltar que a categoria mestiço ou mulato em Angola também obedece, embora aparentemente menos que o Brasil, a algumas variações regionais e a contextos de classe e status (Pereira, 2013). 
posição dos brancos angolanos, que apesar de terem um certo poder econômico são extremamente questionados do ponto de vista nacional, deslegitimados e até estrangeirizados (Pereira, 2013).

Muitas vezes, eu fui confundida como angolana e não era imediatamente percebida como brasileira, ou seja, ser mulata era confortável por um lado, mas um conforto extremamente difícil de lidar porque, afinal, eu não nasci em Angola.

Essa experiência de ser jogada em várias classificações e eu ter que me reposicionar no sistema racial foi o que me permitiu perceber que eu tinha que me posicionar no sistema de classificação religioso para compreender o grupo que eu estava estudando.

Isso para dizer que essa experiência que estou narrando para vocês vai além da minha subjetividade no campo. A minha presença em Angola e entre os Bakongo implicou tanto no descentramento como na politização das posições por mim ocupadas, por vezes fixas, por vezes circunstanciais.

Isso significa que a alteridade na relação da pesquisa não se apresentou como óbvia e foi sendo construída de várias formas. Mais que isso, a relação de alteridade se mostrou instável. Mas certamente sem refletir sobre as posições - sejam elas raciais, religiosas ou nacionais - que eu assumi, ainda que de maneira contingente, não teria feito as descobertas que fiz.

III

Mariza Peirano dedicou muitos dos seus textos para pensar a antropologia brasileira a partir de suas várias diferenças diante das chamadas antropologias centrais e em comparação com tradições nacionais chamadas periféricas, como a Índia, por exemplo. Em seu texto publicado na coleção da "ANPOCS - o que ler nas ciências sociais brasileiras", publicado há 20 anos, Peirano define a alteridade como o aspecto fundante da antropologia. Ela chama atenção para a característica central da antropologia brasileira como uma Antropologia do Brasil, onde não haveria o chamado exotismo que marcaria a antropologia dos países centrais (Peirano, 1999,).

Peirano estabelece uma tipologia da antropologia brasileira a partir de diferentes graus de alteridade, que seriam: 1. alteridade radical, que corresponderia à etnologia indígena; 2 . alteridade amenizada, que corresponderia a grosso modo aos estudos de campesinato e aos estudos de contato interétnico; 3 . a alteridade próxima, que seriam os estudos realizados em meio urbano; e finalmente 4. a alteridade mínima, ou seja, a reflexão brasileira sobre a própria antropologia ${ }^{15}$.

Embora não definindo de forma clara em que é fundada a alteridade, se na distância espacial ou na diferença cultural (Cupta e Ferguson 2008), e mesmo em que termos esta diferença se expressa, no texto de Mariza diferença e alteridade aparecem como quase sinônimos.
15| Mariza Peirano é a antropóloga que mais produziu obras sobre o fazer antropológico brasileiro, a começar pelo seu doutorado. Poderia me referir a mais de uma dezena de artigos ou capítulos onde partes destas discussões reaparecem possibilitando reflexões distintas endereçadas por vezes a públicos diferentes, no caso dos seus artigos em inglês. Como não é a análise de Peirano em si que estamos analisando, mas estamos tomando o seu trabalho como ponto de partida para a nossa discussão, neste texto optamos tomar por referência principalmente o texto publicado na coleção publicada pela Anpocs em 1999. 
Um aspecto importante desta análise é a relação indissociável entre as ciências sociais, tradição onde se insere a antropologia brasileira, e o projeto de nation building que demanda a compreensão ou a definição do que seria o ethos nacional. Ciência social é aqui entendida como comprometida com o princípio da "modernidade iluminista" no qual a nação é abrangida enquanto realidade sui generis, ou seja, em sua singularidade. Isso se traduz por uma certa homogeneidade da construção de seu centro, o que supõe a existência de seus "outros" internos. É desse modo que é possível considerar índios como alteridade radical e camponeses e negros como "seus outros".

Os estudos antropológicos sobre outras realidades fora do Brasil foram definidas por Peirano nesta tipologia como uma outra modalidade de alteridade radical, ainda que com aproximações, no caso de Portugal, ou dos países africanos de língua portuguesa pela suposta aproximação com o universo lusófono que tentei problematizar acima.

Ora, ao relativizar a noção de alteridade da antropologia brasileira por meio da categorização de diferentes "nativos" internos, Peirano define, embora não explicitamente, o lugar do antropólogo brasileiro enquanto um não índio, um não negro, um não camponês. Esse lugar aparece através de um "nós" absolutamente naturalizado" ${ }^{16}$.

É preciso que se diga que eu me refiro a Mariza Peirano pela sua contínua e importante reflexão sobre o fazer da antropologia, mas este "nós" naturalizado que me refiro aparece há muito tempo em vozes e textos de muitos antropólogos brasileiros ${ }^{17}$. O que significa que eu considero as reflexões de Peirano como indicando um certo inconsciente do fazer antropológico brasileiro.

Então se a antropologia é feita por um "nós" que estuda o "outro" brasileiro, qual seria o lugar dos brasileiros negros, indígenas e camponeses que eventualmente se tornam pesquisadores e estudam universos nos quais eles próprios têm proximidade ou pertencimento? ${ }^{18} \mathrm{Ou}$, dito de um outro modo, em que nível epistêmico se situa à chamada "alteridade" que torna possível ser feita a antropologia no e do Brasil? Dito de forma mais provocativa, "Nós quem, cara pálida?"

Eu sempre fui questionada por não estudar "relações raciais". Sendo um corpo distinto daquele dominante no PPCAS/USP de 20 anos atrás, presumia-se que negros estudavam negros assim como estudantes estrangeiros estudam as temáticas dos seus países de origem. Entretanto, do mesmo modo que esta expectativa era criada, também a ideia de "estudar a si próprio" não era bem visto no cânone antropológico pela falta de distanciamento com o objeto.

Ainda que estas questões já estivessem sendo bastante relativizadas pela crítica pós-moderna e pelos estudos de gênero, onde raras vezes se pôs em dúvida a legitimidade e a pertinência do interesse de mulheres pelos estudos sobre muIheres; já os estudos de nós, negros, sobre questão racial, identidade e etnicidade negra, em contrapartida, sempre receberam desconfiança sob a rubrica "estudos de militantes", onde a confusão entre teoria e política, categorias nativas e categorias analíticas se encontravam lamentavelmente misturadas ${ }^{19}$.
16| Ou "nós displicente" no dizer de Osmundo

Pinho (Pinho, 2019: 107).

17| Por exemplo Schwarcz (1999).

$\mathbf{1 8}$ | Sobre novos sujeitos na produção da antropologia ver Alex Ratts (2009), Ângela Figueiredo e Crosfoguel (2007 2010), Osmundo Pinho (2019).

19 | Sobre a emergência do "movimento negro de base acadêmica" no Brasil a partir dos anos 1970 ver Ratts (2009, 2011) 
Assim, a antropologia do ponto de vista nativo, ou seja, do antropólogo ou antropóloga brasileira que estuda seu próprio país, como uma característica fundante da antropologia brasileira, só seria pensável enquanto antropologia feita, internamente ao Brasil, baseada em uma alteridade interna entre os tais "nós, antropólogos" e seus outros, negros, índios, pobres e camponeses. Pois, afinal, somos "os outros" da nação.

Com isso quero dizer que a antropologia brasileira vem traduzindo por alteridade ou distância cultural diferenças que estão calcadas também em distinções de raça, classe e território. As afirmações de Peirano quanto à necessidade de alteridade para a construção da antropologia não deixam claro em que nível podemos situar esta alteridade. Esta é uma ideia disseminada que naturaliza o lugar do antropólogo ou antropóloga como um "nós" que é profundamente marcado pelo lugar racial da branquidade, e social da urbanidade supostamente cosmopolita, de classe alta ou média alta, do sul e sudeste brasileiro (e Distrito Federal).

No momento em que o "outro" emerge como um pesquisador, ele ou ela precisa urgentemente situar-se enquanto um pesquisador ou pesquisadora explicitando sua posição e pertencimento ao seu universo de pesquisa, correndo constantemente o risco de ser deslegitimado pela extrema proximidade, ou pela "militância". ${ }^{20}$

Por outro lado, quando este corpo investigador não toma seu próprio grupo por objeto, algo parece não fazer muito sentido, posto que aos "outros" caberia apenas falar a partir de si próprio, já que não há centramento possível, ou seja, parece não ser adequado para o subalterno ou primitivo falar de outro que não seja de si próprio, pelo ol har naturalizado da sua própria realidade imediata. Afinal, só o olhar universal teria a capacidade de representar, seja a si, seja ao outro (Carvalho 2001; Pinho, 2019).

Assim, o outro, enquanto antropólogo, parece jogar uma partida previamente perdida, pois não está no centro de onde pode ver um outro e não está autorizado a falar sobre si próprio com o distanciamento correto.

Qual é portanto o lugar de fala da chamada antropologia brasileira? Ou seja, de onde ela tem falado? Se o olho que vê é o olho da tradição, segundo Boas, ou se o situar-se geertziano permite a dialogia cultural que é marca da hermenêutica antropológica, sem a qual não podemos interpretar interpretações, nossa antropologia parece falar de um certo lugar da chamada "cultura brasileira" esse constructo em parte criado e em parte desvendado pelas ciências sociais (Pechincha, 2006).

Ora, a noção de brasilidade teve por marca a ocultação e invisibilização das marcas étnicas de africanidade e de indigenidade ${ }^{21}$, em nome da criação da chamada cultura brasileira, caracterizada, entre outros aspectos, pelo racismo cordial, pela miscigenação institucionalizada, balizada pelo branqueamento, e pelo apagamento e minimização dos conflitos como seu ethos central.

Assim, essa antropologia "feita em casa" consegue epistemologicamente resolver o problema da alteridade produzindo sua própria alteridade doméstica, que
20| Para uma crítica a falsa dicotomia entre pesquisa acadêmica e ativismo ver Patrícia Hill Collins (2000)

21 | Sobre "Améfrica" ver Lelia Conzales (1988). 
são os próprios outros do Estado nacional-negros, índios, camponeses, pobres-mas toma a si própria como autor não situado. Embora reconheçamos o engajamento político com que é feita a antropologia e as ciências sociais brasileiras, engajamento ${ }^{22}$ hoje já não é mais o suficiente para desconstruir o ponto de vista supostamente "universal" de onde a antropologia brasileira se pensa ${ }^{23}$.

IV

Os giros críticos da antropologia quanto à posição do sujeito nos permitiram aprofundar o princípio hermenêutico que implica a importância de situar-se, ou seja, a importância do contexto para produzir interpretação e análise (Geertz, 1989 [1973]). Isso tem a ver com a dimensão intersubjetiva que permite a interpretação. Esse movimento também produziu uma ruptura nos procedimentos habituais de objetificação e distanciamento clássicos do fazer antropológico (Clifford e Marcus 1986; Marcus e Fischer 1986).

Esse mesmo movimento também problematizou a noção de autoria introduzindo uma ambiguidade que permite manter o "nós" da neutralidade da ciência tensionado com a autoria de caráter literário que exige a chamada presença do autor através da escrita etnográfica (Ceertz, 1988; Foucault, 1992 [1969]).

Toda esta crítica da autoria se deteve mais nos aspectos retóricos de legitimação da autoridade etnográfica e pouco no lugar mesmo da ciência antropológica como produção de saber/ poder sobre o outro e da manutenção da própria noção de outro e de alteridade como centro da reflexão antropológica. Isso quer dizer que o giro crítico da antropologia chamada pós-moderna se restringiu muito mais aos problemas que implicam a representação, mas não problematizou a própria produção teórica no sentido de que pudesse repensar o lugar de universalidade que a antropologia, ou por extensão, as ciências sociais, construiu para si (Carvalho, 2001).

Tivemos que esperar pela teoria pós-colonial, ou seja, uma reflexão vinda de fora das ciências sociais, que finalmente pôde deslocar o lluminismo como evento chave da narrativa triunfante da modernidade para o drama colonial e para ideia de uma modernidade descentrada. A modernidade passa a ser entendida como construída no interior da expansão colonial, fenômeno este que é percebido a partir de então como condição para a emergência do capitalismo, e não mais como seu mero desdobramento ${ }^{24}$.

A teoria decolonial, desenvolvimento mais recente do movimento pós-colonial, nos permite reposicionar raça e gênero, que até então eram enquadrados como um resíduo dos aspectos indesejados da modernidade, para o centro de sua constituição. Ou seja, os processos de racialização e generificação passam a ser observados como estruturais da produção da modernidade, sem os quais não é possível compreender o capitalismo e os vários modos de produção hierarquizados em seu interior (Quijano, 2005; Mignolo, 2003) 25.
22 |Ver Howard Becker (1977) sobre a noção do viés inerente à sociologia na sua aproximação simpática aos grupos que estuda. $O$ ponto aqui não é evidentemente criticar o engajamento dos cientistas sociais. Entretanto, mesmo sendo de extrema complexidade as diferentes dimensões deste engajamento, cabe reiterar a distinção entre antropologia engajada e a posição do sujeito enquanto constitutiva da própria produção do conhecimento antropológico ou sociológico. Para uma discussão aguda sobre antropologia engajada ver Fonseca (2002).

23| Mônica Pechincha (2006) desenvolve uma discussão profunda sobre o naciocentrismo da antropologia brasileira e a universalização da teoria como elementos centrais para a produção da neutralização da posição do antropólogo frente aos outros internos, cuja alterização é produzida neste processo. Ver também José Jorge Carvalho (2001).

24 | Como já sabido, o pós colonialismo não forma grupo homogêneo, mas pode ser observado em diferentes movimentos e orientado por diferentes disciplinas e correntes. Entretanto, Homi Bhabha (1998), Stuart Hall (2003), Dipesh Chakrabarty (2001) e Partha Chaterjee (2004) são alguns dos autores que permitem perceber esta mudança na forma de descrever a modernidade.

25 | Para uma crítica feminista à formulação da decolonialidade do poder de Aníbal Quijano, ver Maria Lugones, 2008. 
A partir desta perspectiva podemos decupar este "nós" que se coloca no lugar não olhado de onde se vê o outro. Ou seja, o olhar naciocêntrico a partir do qual a antropologia brasileira pôde representar seus outros, pois fala a partir do lugar da ciência nacional brasileira como centro reduplicado da modernidade de onde nomeia e representa seus outros periféricos nacionais.

Finalizando esta reflexão, gostaria de dizer mais concretamente que não é mais possível ao discurso antropológico a manutenção deste lugar de reprodução da modernidade central. Isto significa que é necessário politizar o lugar de fala ${ }^{26} \mathrm{dos}$ antropólogos, das antropólogas e da antropologia - ou seja, sua posição de raça, classe, gênero e sexualidade ${ }^{27}$, em uma academia racializada, generificada, elitizada, urbanocêntrica ${ }^{28}$, tensionando as normativas que reproduzem a espacialidade e a temporalidade coloniais.

A proposta é superar a limitação de pensar raça e gênero apenas pelo elo "subordinado". Isso vale para vários aspectos da investigação, começando pelo lugar do investigador. O sujeito branco é também racializado (Bento, 2002; Sovik, 2009). A raça não pode ser atribuída somente ao não-branco, da mesma forma que o gênero não deve ser apenas atribuído às mulheres. Apesar de esta reflexão parecer ser lugar comum nas pesquisas, vale ressaltar que forjar e manter uma "neutralidade racial" no interior da academia ajuda a perpetuar o perfil de uma antropologia colonizada e colonizadora.

Assumir a racialização que sempre marcou o lugar do outro éassumir o aspecto fundamentalmente relacional da produção de sentido, não apenas de identidade, mas sobretudo de conhecimento. Não é mais possível às ciências sociais brasileiras habitarem este lugar da universalidade ocidental - lugar que nos engloba, mas não nos pertence.

É preciso nos descentrar a partir da posição instável que interrogue a branquidade brasileira para ser possível a construção de um conhecimento que supere a própria noção de alteridade.

Esta pode ser a condição também de, operando pela subversão das experiências habituais de marcação e neutralidade racial, superá-las em prol de outras formas de relação mais horizontalizadas e libertadoras.

Luena Nascimento Nunes Pereira é professora do PPCCS da UFRR]. Formada em Ciências Sociais pela UFR], Mestre e Doutora em Antropologia Social pela USP, realiza pesquisa sobre Angola, identidade étnica e nacionalismo. Publicou o livro "Os Bakongo de Angola: Etnicidade, Política e Parentesco num bairro de Luanda". Mais recentemente tem pesquisado e orientado sobre raça e interseccionalidade.
26 | Apesar da banalização da noção de lugar de fala, eu defendo seu significado original na qual aquele que fala assume a posição de onde se constrói o conhecimento, ou seja, a recusa radical de assumir qualquer forma de neutralidade. Isso é distinto da ideia da experiência como fonte de legitimação de um lugar de enunciação político. Para uma discussão extensa sobre o tema ver Ribeiro, 2017.

27|A interseccionalidade sustenta o ponto de vista segundo o qual raça e gênero são construtos sociais de mútua constituição (Crenshaw, 1989; Collins, 2000). As leituras pós-coloniais e decolonais, bem como a antropologia histórica do colonialismo, vêm ampliando esta perspectiva situando a construção no interior do processo de expansão colonial concomitante e a afirmação da ideologia burguesa nas metrópoles em um contexto de luta de classes (McClintock, 2010).

28 | Com a expansão dos campi universitários para o interior do país caberia observar em que medida emergirá um olhar sociológico que produza um maior descentramento do olhar majoritariamente urbano, ou colonizado pelo olhar urbano, que marca a perspectiva das ciências sociais. Diferente da luta indígena e negra no campo da educação, que produziu uma intensa politização desses sujeitos construindoos como um coletivo, o lugar de fala a partir da área rural não aparece com a mesma intensidade. Entretanto, temos várias experiências dentro de algumas universidades onde existe a LEC/Licenciatura em Educação no Campo, onde podemos ver a aparição do lugar do rural na forma de construir o cotidiano universitário. Entendendo a relatividade da oposição e da construção entre rura e urbano, e suas profundas variações, talvez possamos assistir a produção de um olhar distinto, ainda mais quando marcados pela etnicidade como no caso dos quilombolas e de outras formas tradicionais de organização do território.

CONTRIBUIÇÃO DE AUTORIA: Não se aplica. 


\section{REFERÊNCIAS BIBLIOCRÁFICAS}

BECKER, Howard S. 1977. “De que

lado estamos?". In: Uma

Teoria da Ação Coletiva. Rio de Janeiro,

Zahar Editores, pp. 122-136.

BENTO, Maria A S. 2002. "Branqueamento e branquitude no Brasil" In: CARONE I., BENTO M. A. S. (orgs.). Psicologia social do racismo: estudos sobre branquitude e branqueamento no Brasil. Petrópolis, Vozes, pp. 25-57.

BHABHA, Homi. 1998. O Local da Cultura. Belo Horizonte, Editora UFMG.

CARVALHO, José Jorge de. 2001. “O olhar etnográfico e a voz subalterna”. Horizontes Antropológicos, 7, n. 15: 107-147.

CHAKRABARTY, Dipesh. 2001. "Postcolonialismo y el artificio de la historia: ¿Quién habla por los pasados 'indios'?”. In: MIGNOLO W. (Org.). Capitalismo y geopolítica del conocimiento. Buenos Aires, Ediciones del Signo/Duke University, pp. 133-170.

CHATTERJE, Partha. 2004. "A nação em tempo heterogêneo". In: Colonialismo, Modernidade e Política. Salvador, Edufba.

CLIFFORD, James e MARCUS George (org.). 1986. Writing Culture - The Poetics and Politics of Ethnography. California University of California Press.

COLLINS, Patricia Hill. 2000. Black feminist thought: knowledge, consciousness, and the politics of empowerment. Nova York/Londres, Routledge.
CRENSHAW, Kimberlé. [1989] 1991. "Demarginalizing the Intersection of Race and Sex: A Black Feminist Critique of Antidiscrimination Doctrine, Feminist Theory, and Antiracist Politics". In K. BARTLETT, K. \& KENNEDY, R. Feminist Legal Theory: Readings in Law and Cender, San Francisco, Westview Press, pp. 57-80.

FIGUEIREDO, Ângela e GROSFOGUEL, Ramón. 2007. "Por que não Guerreiro Ramos? Novos desafios a serem enfrentados pelas universidades públicas brasileiras". Ciência e Cultura, Campinas, v. 59, n. 2: 36-41]. FICUEIREDO, Ângela e GROSFOGUEL, Ramón. 2010. "Racismo à brasileira ou racismo sem racistas: colonialidade do poder e a negação do racismo no espaço universitário". Sociedade e Cultura, 12, n. 2: 223-234.

FONSECA, Claudia. 2002. "Antropologia e cidadania em múltiplos planos". Debates. $\mathrm{NACl}$ : Núcleo de Antropologia e Cidadania. Disponível em: https://www.ufrgs.br > naci > documentos > humanas_fonseca. Acessado em 13 de janeiro de 2020.

FOUCAULT, Michel. [1969] 1992. O que é um autor? Lisboa, Passagens.

FREYRE, Gilberto. [1933] 2003. Casa Grande e Senzala. São Paulo, Clobal Editora. 1953 .Um brasileiro em terras portuguesas. Rio de Janeiro, José Olímpio. [1953] 2001. Aventurae

Rotina: Sugestões de uma viagem à procura das constantes portuguesas de caráter e ação. Rio de Janeiro: Topbooks/Univercidade Editora. 
FRY, Peter. 1991. "Politicamente Correto num Lugar, incorreto noutro?". In: Estudos AfroAsiáticos, Rio de Janeiro, n. 21. pp. 167-177. . 2003. "Culturas da diferença: sequelas das políticas coloniais portuguesas e britânicas na África Austral". AfroÁsia, Salvador, n. 29/30: 271-316. 2005. A persistência da raça: ensaios antropológicos sobre o Brasil e a África austral. Rio de Janeiro, Civilização Brasileira.

GEERTZ, Clifford. 1988. Obrase vidas: o antropólogo como autor. Rio de Janeiro, Ed. UFR]. [1973] 1989.

A Interpretação das Culturas. Rio de Janeiro: LTC.

GUPTA, Akhil, FERGUSON, James. 2008. "Más allá de la "cultura": espacio, identidad y las políticas de la diferencia". Antipod. Rev. Antropol. Arqueol., n.7: 233-256.

HALL, Stuart. 2003. Da diáspora: Identidades e mediações culturais. Belo Horizonte, Editora UFMG.

HARRISON, Faye. 2012. "Racism in the Academy: Toward a Multi-Methodological Agenda for Anthropological Engagement". University of Florida. Additional findings of the Commission on Race and Racism in Anthropology and the American Anthropological Association. February. Disponível em s3.amazonaws. com/rdcms-aaa/files/production/ public/FileDownloads/pdfs/cmtes/ commissions/upload/02_Harrison-2.pdf. Acessado em 13 de janeiro de 2020.

LIMA, Viviane de Souza. 2017. Solidariedade atlântica: Movimento brasileiro em apoio às independências africanas, entre percursos e conexões (1961-1975), dissertação de mestrado em História Social, UFMG.
KRENAK Ailton. 2018. "A Potência do Sujeito Coletivo". Entrevista concedida a Jailson de Souza e Silva. Revista Periferia, vol. 1, n. 1. Disponível em: http://revistaperiferias.org/ materia/a-potencia-do-sujeito-coletivoparte-i/. Acessado em 13 de janeiro de 2020.

\section{MARCUS, George E. e FISCHER Michael.} 1986. Anthropology as Cultural Critique: An Experimental Moment in the Human Sciences. Chicago, Chicago University Press.

MARGARIDO, Alfredo. 2000. A Lusofonia e os Lusófonos: Novos mitos portugueses. Lisboa, Edições Universitárias Lusófonas.

LUCONES María. 2008. Colonialidady Cénero. Tabula Rasa, jul-dic, n. 9: 73-101.

MBEMBE, Achille. 2018. Crítica da Razão Negra. São Paulo, N-1 Edições.

MCCLINTOCK, Anne. 2010. Couro imperial: raça, gênero e sexualidade no embate colonial. Campinas, Editora da Unicamp.

MICNOLO, Walter. 2003. Histórias locais - projetos globais: colonialidade, saberes subalternos e pensamento liminar. Belo Horizonte, Editora UFMG.

NOVAES, Regina Reyes. 1994. "Religião e política: sincretismos entre alunos de Ciências Sociais". Comunicações do ISER, n. 45: 62-74.

PECHINCHA, M. T. S. 2006. O Brasil no Discurso da Antropologia Nacional. Goiânia, Cânone Editorial.

PEIRANO, Mariza. 1999. "Antropologia no Brasil (alteridade contextualizada)". In: MICELI, Sergio (org.). O que ler na ciência social brasileira (1970-1995). Antropologia (volume I). São Paulo, Editora Sumaré, pp. 225-266. 
PEREIRA, Luena. 2000. Os Regressados na cidade de Luanda: um estudo sobre identidade étnica e nacional em Angola, dissertação de mestrado em Antropologia Social, Universidade de São Paulo. 2005. Os

Bakongo em Angola: religião, política e parentesco num bairro de Luanda, tese de doutorado em Antropologia Social, Universidade de São Paulo. 2013. "Identidades

racial e religiosa em Angola e no Brasil: reflexões a partir da experiência em campo em Luanda". In DULLEY, I. EJARDIM. M. (orgs.). Antropologia em Trânsito: reflexões sobre deslocamento e comparação. São Paulo, Annablume, pp.59-89. 2015 Os Bakongo de

Angola: Etnicidade, Política e Parentesco num bairro de Luanda. Rio de Janeiro, Contra Capa.

PINHO, Osmundo. 2019. "A antropologia no espelho da raça". Revista do PPCCS-UFRB -Novos Olhares Sociais. Vol. 2. n. 1: 99-118.

QUIJANO, Anibal. 2005. "Colonialidade do poder, eurocentrismo e América Latina". In: LANDER, Edgardo (org.). A colonialidade do saber: eurocentrismo e ciências sociais. Perspectivas latino-americanas. Ciudad Autónoma de Buenos Aires, Colección Sur Sur, CLACSO, pp.227-278.
RATTS, Alex (Alecsandro J. P.). 2009. "Encruzilhadas por todo percurso: individualidade e coletividade-movimento negro de base acadêmica". In: PEREIRA, Amauri Mendes; SILVA, Joselina da (org.). Movimento Negro Brasileiro: escritos sobre os sentidos de democracia e justiça social no Brasil. Belo Horizonte, Nandyala Editora, pp. 81-108. 2011.

"Corpos negros educados: notas acerca do Movimento Negro de base acadêmica". Nguzu, ano1, março/julho, n. 1: 28-39.

RIBEIRO, Djamila. 2017. O que élugarde fala? Belo Horizonte, Letramento.

SCHWARCZ, Lilia K. Moritz. 1999.

"Questão racial e etnicidade". In: MICELI, Sergio (org.). O que ler na ciência social brasileira (1970-1995). São Paulo, Editora Sumaré/ ANPOCS; Brasília, CAPES.

SILVA, Vagner Conçalves da. 2000. 0 antropólogo e sua magia: trabalho de campo e texto etnográfico nas pesquisas antropológicas sobre as religiões afro-brasileiras. São Paulo, Edusp.

SOVIK, Liv. 2009. Aqui ninguémé

branco. Rio de Janeiro, Aeroplano.

SPIVAK, Gayatri. 2010. Pode o subalterno falar? Belo Horizonte, Editora UFMC.

VALE DE ALMEIDA, Miguel. 2007. "O Atlântico pardo: Antropologia, colonialismo e o caso 'lusófono"'. In BASTOS, C., ALMEIDA, M. Vale de e FELDMAN-BIANCO, B. (org.). Trânsitos Coloniais: Diálogos críticos lusobrasileiros. Campinas, Unicamp, pp.27-43.

Recebido em 5 de maio de 2020. Aceito em 4 de junho de 2020. 